\title{
A BSTRACTS
}

\section{EAR}

Primary Thrombosis of the Mastoid Emissary Vein. J. Hyвaseк. (Oto-Laryngologia Slavica, August 1930, Vol. ii., Fasc. 3.)

Primary thrombosis of the mastoid emissary vein arises in much the same way as thrombosis in the lateral sinus, that is to say, most commonly by a direct contact with infection and spread thereof, or less often by a spreading thrombo-phlebitis from the venules of the bone draining into it. In cases of perisinus abscess the pus frequently tracks outwards along the line of the emissary vein, and by compression and consequent interruption of the blood stream may cause thrombosis.

Spread of the thrombosis tends to be against the blood stream, i.e. towards the periphery rather than towards the sinus.

The thrombosis may be symptomless or may give rise to septicæmia, and probably accounts for those cases with the clinical symptoms of lateral sinus thrombosis without demonstrable thrombus in the sinus itself.

Flow of blood from the vein does not prove that the sinus itself is free from clot, which may be either mural or occluding it.

Regarding treatment, the author advises removal of the vein in its osseous course and in all cases advises exploratory puncture of the sinus itself, advising three punctures close to the junction of the vein and sinus. If the clot is confined to the vein itself he does not recommend any further treatment; if it has spread to the sinus, ligature of the jugular vein and obliteration of the sinus, etc., must be considered.

E. J. Gilroy Glass.

\section{The Rôle of the Mastoid Emissary Vein in the Production of Non- Obstructing Sinus Thrombosis. Prof. Reversial, Lille. (O.R.L. Internationale, Vol. xiv., No. 7.)}

The author points out that many cases of septicæmia of aural origin have no signs of thrombus in the lateral sinus, and these cases he considers are frequently due to thrombosis of the mastoid emissary vein. He quotes a case in which the vein showed demonstrable thrombosis whereas the sinus itself was patent, and in which the patient had septicæmia and died of a metastatic pneumonia and empyema.

E. J. Gilroy Glass.

\section{Post-Operative Thrombosis of the Lateral Sinus. J. RAMARDen, Paris. (O.R.L. Internationale, Vol. xiv., No. 7.)}

The occurrence of lateral sinus thrombosis and septicæmia following mastoid operations is described, and the view is expressed that 202 


\section{Ear}

this may be caused by a perforating wound in the sinus, which would probably be noticeable at the time, or by a simple exposure of the sinus, in which case there might be some minute and unnoticed wounding of the sinus wall. He quotes a case in support of this latter possibility.

$\mathrm{He}$ advises that in mastoid operations the sinus should not be exposed unless the clinical condition warrants it, and that if it be exposed, that the first dressing should be done the following day and thereafter the wound dressed daily. If the sinus wall be perforated, he advocates the advice of Bourgeois:-First to complete the operation in spite of the hæmorrhage, and secondly to cover the wound in the sinus wall with a small tampon, kept in position by the ordinary mastoid dressing which should be changed daily, the tampon on the sinus being removed on the fourth day and renewed if hæmorrhage recommences.

E. J. Gilroy Glass.

Vincent's (Fusospirillary) Infection of the Ear. L. H. BARENBERG and J. M. Lewis, New York. (Journ. Amer. Med. Assoc., 5th April r930, Vol. xciv., No. I4.)

Three cases are reported, all in young, poorly nourished children. Either an acute or chronic otitis media preceded Vincent's infection. In all cases there was a sudden appearance of a profuse, fotid, and bloody aural discharge accompanied by swelling of the external canal, the presence of a dirty greyish membrane and swelling of the posterior auricular gland. The local application of ro per cent. solution sulpharsphenamine and intramuscular injection of 0.2 gr. of the same brought about a cure in forty-eight hours.

The article occupies three columns.

\section{Angus A. Campbell.}

Relation of Infection of the Ear and Infection of Intestinal Tract in Infants. Results of Five Years' Study. D. E. S. WISHART. (Journ. Amer. Med. Assoc., i Ith October 1930. Vol. xcv.; pp. I 084-1089.)

Many references are given which support the view that infection in the mastoid antrum is the cause of acute intestinal intoxication in infants.

The Medical Staff of the Hospital for Sick Children, Toronto, believe that the type of the disease seen in Toronto is essentially the same as that which exists in other parts of Canada and the United States. Study of the disease has been pursued seriously for five years. For the last two years a large body of workers have co-operated.

The facts and figures used are drawn from an elaborate study of all pertinent records for five consecutive years-from 1925 to 1929 


\begin{abstract}
s
inclusive-at the Hospital for Sick Children, Toronto. The statistics and conclusions have the consideration and approval of the physicianin-chief and his research department and the pathologist and his department. The relationship of infection of the paranasal sinuses is not considered in this report.

The onset of the disease is rarely characterised by a "cold." The great majority of the infants were without any clinical evidence of an infection of the upper respiratory tract at the time they were toxic. Many infants remained without any infection of the ear throughout the whole course of the illness. Both ear-drums of many showed abnormality immediately preceding death. This change is an antemortem phenomenon due to forcible ejection up the Eustachian tubes. When infection of the mastoid exists, it is the result and not the cause of the child's lowered condition.

Accumulations or infections found in the mastoid antrum of infants at autopsy are ante-mortem in origin.

Puncture of the mastoid antrum for diagnosis of latent mastoiditis is not to be recommended. Bilateral operation on the mastoid as a cure for the disease was a failure. Operation is to be postponed as long as possible. The autopsies of two intensively studied series of cases of acute intestinal intoxication show that mastoid infection was not common.
\end{abstract}

There was no correspondence between the bacteriology of the infection in the upper respiratory tract and that in the intestinal tract. Evidence is being accumulated to show that the disease is of intestinal origin.

The author concluded that infection of the mastoid antrum is not the cause of acute intestinal intoxication in infants.

Author's AbSTRACT.

Histological Studies with regard to the Development of Cholesteatoma. W. Döderlein, Berlin. (Zeitschrift für Hals-, Nasen- und Ohrenheilkunde, Band xxvi., Heft 5, p. 530.)

In reference to the mode of development of middle-ear cholesteatoma Döderlein considers that there is no doubt that the epidermis extending into the middle ear originates without exception from the epidermis of the skin of the meatus or tympanic membrane which spreads into the middle-ear cavities in different ways. There is as yet no evidence that epithelial metaplasia takes place in the course of chronic middle-ear inflammation, there is however always the possibility of such an occurrence on the analogy of similar epithelial metaplasia in other parts of the body. The simplest and most frequent mode of the penetration of epidermis is the inward proliferation through a perforation in the membrane, or, less frequently, through a bony 204 


\section{Ear}

fistula in the meatus. In the membrane it is usually through a marginal perforation, because larger areas deprived of epithelium are to be found there, which become covered by the neighbouring epidermis. Further penetration of the epidermis requires that the neighbouring areas of the epithelium in the middle ear are defective, that is to say, either destroyed by the inflammatory process or thrown off. The two forms of epithelium meet or join so intimately that the one passes directly into the other. A second mode of penetration of the epidermis into the cavities of the middle ear is due to the invagination of the membrane in Shrapnell's region; this may enlarge into a bigger sac filled with broken-down epidermic cells. This may then rupture inwards and lead to inflammation of the middle ear by the entrance of infective material. A third form of the entrance of epidermis is a proliferation inwards of the epidermic layer covering the membrane in the form of papillary ingrowths which proliferate and ramify in the subjacent connective tissue.

There are thus three methods by which epidermis can extend in the middle-ear cavities:-(I) a simple skinning over of membrane which has lost its epithelium; (2) from purely mechanical causes; (3) the dipping capacity of the epidermic cells to proliferate into the subepithelial tissue. There are, therefore, two processes ( $\mathrm{r}$ ) an inflammatory ingrowth of epidermic cells and their spread in the tissues which have been damaged by an inflammatory process : (2) after the subsidence of inflammation, the masses of residual epithelial cells may take on the form of actual cholesteatomatous tumours. Clinically the two processes merge one into the other. On comparing cholesteatoma with carcinoma there is some resemblance, as both tumours have as their essential constituent the inward growing epidermis, but leading in one case to the formation of a benign and in the other of a malignant neoplasm.

James Dundas-Grant.

Pneumatisation of the Temporal Bone in Otosclerosis, as shown by Röntgenography. J. G. Dillon, and B. S. Preobraschensky, Moscow. (Zeitschrift fïr Hals-, Nasen- und Ohrenheilkunde, Band xxvi., Heft 5, p. 537.)

Fifty cases of otosclerosis, making in all 'one hundred temporal bones, were examined. They fell into three groups:-(1) with wellmarked pneumatisation; (2) with the pneumatic on one side and with the mixed type on the other; (3) with well-marked sclerotic mastoids. The following conclusions are arrived at: (I) that in cases of otosclerosis pneumatisation of the temporal bone may be just as various as in normal persons; (2) the structure of the temporal bone has no obvious influence on the course of the otosclerosis; (3) the

VOL. XLVI. NO. III. 


\section{Abstracts}

limited, generally small, area of the disease in the capsule of the labyrinth has no influence upon the structure of the rest of the bone. The development of the pneumatisation of the temporal bone, in great part at least, has come to an end before the otosclerotic process has started. Disturbance of function of the endocrine glands only occurs later on and is not sufficiently intense to bring about any very obvious changes in the temporal bone as a whole.

James Dundas-Grant.

An Oculo-motor Reflex excited by Sound in very Deaf Subjects. E. Fröschels, Vienna. (Zeitschrift für Hals-, Nasen- und Ohrenheilkunde, Band xxvi., Heft 5, p. 5 I r.)

In the pigeon, reflex movements of the head in the fronto-occipital axis, away' from the side of the source of sound, are excited when a loud sound is directed into the ear. In mammals there is associated with the head-movements an analogous movement of the eyes, and when a'semicircular canal is destroyed the movement is in the plane of this canal. Tullio found a similar reflex in human subjects if in an absolutely dark chamber they fixed their eyes on a single spot of light, the eyes moving when a tuning-fork sounded in contact with the head or near the ear.

Fröschels tested II 8 deaf-mutes or extremely deaf persons by means of Urbantschitsch's harmonicon and found that in 50 there was a positive reaction, and that 45 of these showed eye-movement with or without movements of the head, 5 only with head-movements. The reaction appears to be stronger from the better ear. It is evident that the stimulus acts through the cochlear nerve and not alone through the nerves which convey feelings of vibration. (It is interesting to note that de Burlet found a nerve connection between the cochlea and the special portion of the vestibular nerve which supplies the saccule and the posterior semicircular canal. Wooland's Recent Advances in Anatomy, 1927, p. 177 J. D.-G.) James Dundas-Granr.

Phenomena pertaining to the Nervous System in Morbus Ménièri. S. H. Mygind and Dida Dederding. (Acta Oto-Laryngologica, Vol. xiv., Fasc. 3-4.)

In 135 patients, headache was found in $9 \mathrm{r}$ per cent., generally localised to the side principally affected by the ear disease. It was usually of a distinctly paroxysmal character, increasing and decreasing in sympathy with the ear phenomena. Like these it was often worst in the morning. Tenderness of the processus mastoideus (Bárány's symptom) was found in 7 cases. The relation between headache and water metabolism was evident in many cases. Abnormal content or cells in the cerebrospinal fluid was found in $9 \circ$ per cent. The lumbar 206 


\section{Ear}

pressure also was generally increased in the cases examined. Weakness of the memory and mental depression, often in connection with mental irritability, were frequently seen, but, as a rule, only in the bad periods. A feeling of general fatigue, especially in the bad periods, was found in 80 per cent. of the cases. Paræsthesias, particularly in fingers and toes, were frequent in the bad periods. Tetanic postures of the fingers were observed in 3 cases. Transient paresis of the abducent nerve was seen in 2 cases, of the facial nerve in 3 cases. The rare occurence of medullary symptoms speaks against the aural phenomena originating in the medulla oblongata. The cerebral, as well as the aural phenomena would seem to be most rationally explained by the two unyielding liquor systems; the cranial and the labyrinthine cavity being affected by parallel processes consisting in an intracellular œdema, which, as far as the brain is concerned, probably is principally localised in the meninges.

AUTHOR's SUMmaRY.

Tic of Salpingopalatinus Muscle causing Sound audible to Bystander. Henry F. Stoll, Hartford, Conn. (Journ. Amer. Med. Assoc., I 3 th September 1930, Vol. xcv., No. I 1.)

The author reports the case of a mentally deficient man, aged 30 , complaining of ticking in his ears. The observer could hear the sound 20 inches away from the patient's left ear. It was perfectly rhythmic (132 to the minute) but was not synchronous with the pulse-rate. Pharyngeal and laryngeal examinations were negative. With a nasopharyngoscope a rhythmic contraction of the narrow muscle running along the anterior border of the left Eustachian tube was observed. It was a "vertical nystagmus," and with each contraction the orifice of the Eustachian tube could be seen to open and close. The muscle was thought to be the salpingopalatinus. The patient's mother stated that the noise was inaudible when the patient slept. Treatment was unsuccessful.

Angus A. Campbell.

On the Professional Traumatisation of the Ear of Industrial Workers.

N. Losanov, Saratov. (Acta Oto-Laryngologica, Vol. xiv., Fasc. 3-4.)

The writer began by making a study of the damage to the hearing mechanism in workers at the Lenin nail and bolt factory at Saratov, and also decided to place dogs and rabbits in the factory. This is a very noisy place because of the sound produced by the nail-stamping machines. There are about II 5 of these machines, and the pitch of the tone produced depends upon the size of the nail being stamped. Middle tones prevail, and the noise is sufficiently great to make it difficult to hear loud speech close to the ear. 


\section{Abstracts}

As part of the clinical investigation the cases of ten affected workers are described in detail, and the following conclusions are drawn.

I. The injury affects especially the phonoreceptory function.

2. Slight affections of the statoreceptory function are seen only in a small number of cases and in those with complications (sinus disease, intoxications, etc.).

3. The phonoreceptory apparatus is affected in toto.

4. The perception of combined sounds is affected more than that of elementary ones.

5. Long rest from work allowed of some degree of recovery only.

6. Cotton-wool plugs did not protect.

7. Nasal and accessory sinus disease acted as aggravating factors.

The experimental side of the work deals with eight groups of animals :-

\section{Group.}

Eight rabbits submitted to the daily effect of noise, except holidays, during eight hours with an hour's intermission for dinner, for a period of five months.

The microscopic study of the external and middle ear when compared with control animals showed no change, but a similar examination of the inner ear revealed grave alterations, especially in the middle cochlear helix. There was destruction of the organ of Corti and atrophic degeneration of the peripheral neuron with a partial loss of cells and fibres. The basilar and superior helices, however, were affected considerably less severely.

\section{Group.}

Six rabbits under similar conditions but with an extra day of rest on Thursdays. The damage in the cochlea was found to be less severe in this group.

\section{Group.}

Three rabbits submitted to the influence of noise for three months, but with a condition of nasal obstruction produced experimentally. The interference with nasal respiration in this group was a marked contributory cause to the damage in the cochlea.

$$
\text { IV. Group. }
$$

Five rabbits under similar conditions to Group I., but with their cages suspended from the ceiling by long steel springs, and therefore not in contact with the floor. This group only differed from Group I. in that the membrana tectoria was not affected.

\section{Group.}

Six rabbits placed under the conditions in Group I., but before being pathologically examined they were put under normal conditions 208 


\section{Nose and Accessory Sinuses}

for four months. Subsequent microscopic examination of the cochlea revealed some tendency to regeneration of the nerve cells in the ganglion spirale.

\section{Group.}

Four dogs submitted to the effect of noises for three months under conditions similar to the animals in Group I. Sound-conducting apparatus was found to be undamaged, and in the cochlea only slight degeneration of the perceptive apparatus was noted.

\section{Group.}

Three dogs under conditions as in Group VI., but the animals breathed through tracheotomy cannulæ. Not only was a marked cochlear degeneration found in these animals in the middle helix, but a similar change was found in tracheotomised dogs kept in silent surroundings, although for a longer time.

\section{Group.}

Three dogs with artificially (mechanically) produced suppurative rhinitis during the period of three months, though otherwise as in Group I. No change was found in the middle ear, but degenerative changes were found in the cochlea.

The condition of the nose and accessory sinuses apparently has a detrimental effect even on the inner ear mechanism.

In comparing the clinical data of this work with the experimental, it is noticed that in workers who have been busy in the factory for as long as two years no decline of hearing power could be noted, whereas much damage is brought about in rabbits under the same conditions during a period of five months.

On the other hand, it is reasonably suggested that a period of five months is a considerably lesser proportion of human life than of the life of rabbits.

The cause of the more serious injury to the middle helix of the cochlea is found in the character of industrial noise, in which there is an absence of the highest and lowest tones.

The article is illustrated with a number of microphotographs.

$$
\text { H. V. Forster. }
$$

\section{NOSE AND ACCESSORY SINUSES.}

The Rational Surgical Treatment of Chronic Antral Disease. JoHn C. Hunt, London, Ont. (The Canadian Medical Association Journal, September 1930.)

\section{Summary.}

r. Thanks largely to improved X-ray technique and the growing use for diagnostic purposes of iodised oil injection, it has become recognised that a large percentage of all cases of chronic nasal catarrh, 


\section{Abstracts}

and many remote systemic diseases, are directly due to chronic sinusitis, the antrum being the largest sinus and the one most frequently involved.

2. The nasal and naso-antral methods of operating for this trouble seldom give permanent relief, and not infrequently they only serve to increase the disability.

3. The extra-nasal antrum operation (Caldwell-Luc), miscalled the "radical," is the only one which takes proper cognisance of the true character of the underlying pathological condition of chronic nasal sinusitis, i.e., the chronically infected and permanently thickened mucosa, and by completely removing the same, offers a safe and sure cure of an otherwise intractable disease. KeITH Hutchison.

The Sneezing Reflex. O. KöRNER, Rostock. (Zeitschrift für Hals-, . Nasen- und Ohrenheilkunde, Band xxvi., Heft 3, p. 349.)

Professor Körner believes that sneezing in the ordinary way is effected through the mouth and thus fails in its proper purpose, namely, the clearance of the nose. He observes that little children sneeze through the nose, as is shown by the "stalactites" of mucus on the upper lip. It is only when we are taught habits of cleanliness that we shunt the outflow of air and mucus from the nose to the mouth.

James Dundas-Grant.

Does the Idea of "Vacuum Sinus" rest on a Scientific Basis? Should it be Retained as a Clinical Entity? J. Bourguet. (Oto-RhinoLaryngologie Internationale, Vol. xiv., p. 8.)

The author holds that the idea is untenable on the grounds that :-

(I) Sluder's cases frequently suffered from other diseases which might have caused the symptoms.

(2) Anatomically it would be practically impossible to have a sinus empty of air in the absence of inflammation.

(3) Sluder's hypothesis that the eye muscles could cause traction on the floor of the sinus is anatomically incorrect.

(4) Ewing's sign (pain on pressure in supero-internal part of orbit) is due to the presence of nerves in this situation. (Sluder has stated that there is no nerve in this situation.)

E. J. Gilroy Glass.

Osteomyelitis of the Skull. Report of Cases Occurring as a Result of Frontal Sinus Infection with Staphylococcus pyogenes aureus. Fletcher D. Woodward, University, Va. (Journ. Amer. Med. Assoc., 27 th September 1930, Vol. xcv., No. 13.)

The direct cause is bacterial infection, usually Staphylococius pyogenes aureus. It is commonest in early adult life as the diploë 


\section{Nose and Accessory Sinuses}

are more marked then. It arises spontaneously or secondary to either intra- or extra-nasal trauma. The sinus ostium becomes occluded, and pus under pressure causes areas of necrosis and venous thrombosis. The infection spreads through the diploëtic veins. The outer table being more porous breaks down first. As the diploëtic veins pass through suture lines, secondary areas may be found in different bones, or on the opposite side. As the dura is highly resistant meningitis or brain abscess are late complications. Sinus thrombosis is not uncommon. Osteomyelitis is characterised by insidious onset, the appearance of soft doughy swellings, persistent septic temperature and later, intracranial symptoms. Stress is laid on preliminary bacteriological study. In both acute and chronic cases the simplest external operation should be employed. If the organisms be Staphylococcus aureus a more radical operation is necessary, and the skull should be resected well beyond the diseased area. The hair should be shaved or clipped closely so that later foci may be detected earlier. The wound should be flooded with chlorinated soda. Repeated transfusions are advised. Three cases are reported, all in young men with negative Wassermann. All were staphylococcal in origin. Two had brain abscess, one being suspected for two months before a definite diagnosis could be made. All got well, although one required four years. The other two have been well for three years.

The article occupies six columns and has a bibliography.

Angus A. Campbell.

Meningitis (Staphylococcus aureus) Secondary to Frontal Sinusitis: Operation and Recovery. Howard C. Ballenger, Chicago. (Journ. Amer. Med. Assoc., Vol. xciv., No. I4, 5th April 1930.)

After a brief review of the literature the author discusses the findings from 297 cases of meningitis admitted to the Children's Memorial Hospital during the past ten years. He then reports the case of a boy, aged 6, admitted to the hospital because of headache, fever, convulsions, and swelling of the forehead and left eyelid. This swelling was diffuse, brawny, tender but without redness or fluctuation. There was rigidity of the neck, positive Brudzinski and positive bilateral Kernig. Ankle clonus was not present. The spinal fluid was turbid, under pressure, and with a two-plus positive Pandy test. The cell count was 320 and Staphylococcus aureus was grown from the culture. Both frontal sinuses were opened externally and were found to be filled with thick yellow pus. The posterior table was removed and similar yellow pus escaped from the dura. Cultures from this yielded Staphylococcus aureus. Three days after the operation pneumonia developed in the left lower lobe. Three abscesses developed over the frontal, parietal and occipital region. Three weeks after the operation there was 


\begin{abstract}
s
complete paralysis of all the muscles of the right eye. Six months later he was entirely well except for a slight discharge from the scalp wound. The white-blood cell count varied from 9000 to 32,000 , and from six spinal punctures Staphylococcus aureus was obtained five times. The spinal fluid cell count ranged from $\mathrm{I} 3^{\circ}$ to $335^{\circ}$. On account of the persistent and long-continued stupor, delirium, high cell count and repeated positive spinal fluid cultures, the author concludes this is a case of recovery from diffuse suppurative meningitis.
\end{abstract}

The article occupies seven columns, has two tables, and a bibliography.

Angus A. Campeell.

\title{
LARYNX.
}

Further Experiences with Artificially Induced Recurrent Paralysis as a Curative Factor in Laryngeal Tuberculosis. H. Schugt. (Münch. Med. Wochenschrift, Nr. 22, Jahr. 77.)

Schugt prefers the blind method of injection suggested by Leichsenring to the operative exposure and actual injection of the nerve trunk as carried out by Von der Hutten. Schugt uses 85 per cent. alcohol to which a few drops of 1 per cent. solution of novocain has been added. He uses an ordinary needle of from 8 to $10 \mathrm{~cm}$. in length. The site of insertion between the cricoid cartilage and the first tracheal ring is marked on the skin. The needle-point is carried to the vertebral column. It is then withdrawn from $\mathbf{I}$ to $\mathbf{I} \frac{1}{2} \mathrm{~cm}$., and from I to $\mathbf{I} \frac{1}{2} \mathrm{c.cm}$. of the solution injected. It is sometimes necessary to repeat the procedure. The danger of wounding vessels or other important structures is practically very small. The paralysed cord adopts the median or the intermediate position. For obvious reasons, only the nerve on the most affected side should be paralysed. The coughing mechanism is not affected. The average duration of the paralysis is from four to eight weeks. It is not certain that the paralysed cord will regain its normal function.

The most favourable cases are those in which the disease is mostly confined to the vocal cord and ventricular band of one side and in which the pulmonary disease is not too far advanced. Schugt has treated 25 cases. Of this number he has had 15 under extended observation. Of these 15 , there were 9 cases which were clinically cured, 3 were not improved, 2 were disimproved, and I case was lost sight of.

The author considers that the treatment is strongly justified by his results and that with combined local and general treatment still better results may be expected.

J. B. Horgan. 


\section{Larynx}

Intralaryngeal Hemorrhage of Septic Origin leading to Death by Suffocation. E. ZImmermann. (Münch. Med. Wochenschrift, Nr. 32, Jahr. 77.)

The record is of a case of septicæmia (Staphylococcus albus) occurring as the result of a badly crushed finger, in which the patient died of suffocation. This latter occurred whilst the patient was straining at stool during an exacerbation of the primary infection which occurred two months after the injury. The course of events suggested pulmonary embolism but the post-mortem examination revealed the presence of a large bilateral subglottic hæmatoma extending from the lower surface of the true cords approximately to the level of the lower border of the cricoid cartilage. (Specimen illustrated.) The causative organism was cultivated from the spleen.

J. B. HoRgan.

Acute Laryngeal Obstruction. Lyman G. Richards, Boston. (Journ. Amer. Med. Assoc., I $3^{\text {th }}$ September I930, Vol, xcv., No. I r.)

The article is based on five years' experience in a large children's hospital. Unless a case be of dire extremity sufficient time is taken to make a correct diagnosis. The patient is admitted to hospital and placed in a quiet room, with a moist atmosphere, at a temperature of $75^{\circ} \mathrm{F}$. No real hypnotic is used. The appearance and behaviour of the patient are carefully watched. The temperature and pulse are carefully charted. In the early stages inspiratory stridor is the outstanding symptom. Cyanosis is a late symptom and should not be waited for. Any increase of restlessness is always a dangerous signal. A steady elevation of the pulse and temperature rate are considered unfavourable. Complete absence of temperature suggests foreign body. In making a diagnosis direct laryngoscopy in skilled hands is the procedure of choice. Appropriate instruments are ready at hand. Foreign bodies if present will usually be found between the vocal cords. Acute streptococcal laryngitis has proved to be the most difficult condition to handle and the most fatal. It is accompanied by high fever, rapid pulse, and general toxæmia. There is intense redness of the glottis, and often so much swelling that the cords are scarcely visible. Rarely is there any membrane. A so-called "Mosher life-saving tube" may be inserted and left in situ during tracheotomy, if this be required. The life-saver is withdrawn before the tracheotomy tube is put in. General medical care is required as bronchopneumonia often develops. In diphtheritic laryngitis the typical membrane is seen in the larynx. This is removed by suction and diphtheria anti-toxin given. If the patient does not do well, intubation is performed, but the tube should not be left in more than 48 hours. If this has to be replaced several times tracheotomy is 


\begin{abstract}
s
performed. In laryngitis sicca,crusts accumulate on the vocal cords to such an extent that intubation may be necessary. Intubation is sometimes necessary in post-operative odema. In obstruction due to extra-laryngeal pressure tracheotomy is preferred.

The article occupies almost nine columns.
\end{abstract}

Angus A. Campbell.

\title{
PHARYNX.
}

Results of Tonsillectomy: A Comparative Study of Trenty-two Hundred Tonsillectomised Children with an Equal Number of Controls Three and Ten Years after Operation. ALBERT D. Kaiser, Rochester, New York. (Journ. Amer. Med. Assoc., 2oth September 1 930, Vol. xcv., No. 12.)

The operations reported in this study were done by ten skilled laryngologists. Complete enucleation of the tonsils was always attempted, and generally the operative results were good.

No account has been made of the lingual tonsil. Apparent benefits during the first few post-operative years are not so evident over a ten-year period. Outstanding benefits are apparent in influencing the incidence of sore throats. Substantial benefits are noted in rendering children less susceptible to scarlet fever and diphtheria, although the latter is influenced by the prophylactic use of toxin-anti-toxin. Acute head colds and otitis media, although definitely lessened over a three-year period, are not essentially influenced over a ten-year period. Cervical adenitis is decidedly reduced. Bronchitis and pneumonia actually occur more frequently in tonsillectomised children. First attacks of rheumatic fever occur almost $5^{\circ}$ per cent. less often in tonsillectomised children, while recurrent attacks are not benefited at all. Chorea occurs as often in children who have been operated on as in children who have not, except that less heart disease is associated with chorea in tonsillectomised children.

The article occupies nine columns and has four charts.

Angus A. Campbell.

\section{Emphysema of the Head and Neck Complicating Tonsillectomy.}

Frederick H. Von Hofe, East Orange, New Jersey. (Journ. Amer. Med. Assoc., 27 th September 1930, Vol. xcv., No. I3.)

Three cases are reported in children between two and four years of age. The tonsils were removed with the La Force-Sluder instrument and ether anæsthesia. In only one case was there undue struggling during induction. The right tonsil was removed first. In every case the emphysema developed on the right side immediately following its removal. There was considerable swelling over the right side 


\section{Pharynx}

of the face, the zygomatic arch, and into the scalp. Crepitation was present throughout the swollen area. No trouble was experienced when the other tonsil was removed. The emphysema completely subsided in from three to five days. Angus A. Campbell.

Radiation Therapy of Tonsils. Leila Charlton Knox, St Luke's Hospital, New York. (Journ. Amer. Med. Assoc., 8th March I930, Vol. xciv., No. Io.)

During the past six years the tonsils were irradiated in 259 patients of whom 14I were followed from three months to six years. Four to eight treatments were given at weekly intervals through a small portal (4 by 6 centimetres). In general, roentgen irradiation should not replace tonsillectomy in the rheumatic child with or without endocarditis. It should not be used in acute tonsillitis, diphtheria, scarlet fever, Vincent's angina, abscess of any type or acute leukæmia. It has been found useful in hypertrophic pharyngitis and in elderly patients who are not good subjects for operation. Injury to the endocrine glands has not been observed, although dryness of the throat sometimes occurs.

The article occupies eight columns and has an extensive bibliography.

Angus A. Campbell.

The X-Ray Treatment of Hypertrophied Tonsils. KLOTZ LoTHAR. (Münch. Med. Wochenschrift, Nr. 41, Jahr. 77, S. I 756.)

Amongst 40 cases treated, the tonsils returned to normal within $2 \frac{1}{2}$ months, sometimes within two weeks. In the method employed the patient lies on the back and turns the head somewhat to one side. The head is steadied by placing a roll beneath the neck. The tube used consists of a glass tube shaped like a speculum, which is introduced into the mouth in the direction of the tonsil which is to be radiated. Errors of direction are avoided by the preliminary introduction of a spatula. At each séance the patient is radiated with a dose of $100 \mathrm{R}$. at $\mathrm{i} 80 \mathrm{~K} . \mathrm{V}$. and 3 M.A., a filter of $0.5 \mathrm{~mm}$. of copper and $\mathrm{I} \mathrm{mm}$. of aluminium being employed. The radiations take place at intervals of two or three days. This may be repeated in eight days and, if necessary, after a further interval of from four to six weeks.

J. B. Horgan.

Should Tonsillectomy be carried out during or soon after an Acute Inflammatory Disease of the Tonsils? S. Levinger. (Münch. Med. Wochenschrift, Nr. 39, Jahr 77, S. I666.)

The author has carried out tonsillectomy in 235 patients suffering from peritonsillar abscess, and in 60 cases immediately following such 


\section{Abstracts}

attacks. He is quite convinced that the book teaching against such procedure is incorrect. He considers that the occasional severe complications following tonsillectomy are due to a too radical removal of the lower pole. When, therefore, he operates in the acute stage he avoids removing the lower pole, a circumstance which he has not found to mitigate against the success of an otherwise radical operation. Levinger considers that not only from the patient's, but from the immediate and remote, point of view, it is preferable to relieve these cases by tonsillar enucleation. In case the patient refuses to allow this course he relieves the patient by separating (under infiltration anæsthesia) the upper pole of the tonsil from the anterior faucial pillar instead of performing the classical incision through the anterior faucial arch.

J. B. Horgan.

\section{ENDOSCOPY.}

The Mechanism of Physical Signs in Neoplastic and other Diseases of the Lung, with especial reference to Atelectasis and Emphysema, Chevalier Jackson, Philadelphia. (Journ. Amer. Med. Assoc., 3oth August I 930, Vol. xcv., No. 9.)

Bronchoscopic observation of foreign bodies has proved the accuracy of localisation of the intruder. This is indicated by the interpretation of the physical signs based on the bronchoscopically discovered mechanism of their production. It has also shown that secretions when dried or viscid may produce the same physical signs as foreign substances, mucosal swellings, granulations, benign and malignant growths. Obstruction of a bronchus is one of the fundamental factors in the etiology of pulmonary disease. Three types of obstruction are mentioned: (I) the stop-valve in which no air passes in or out and the residual air is absorbed (atelectasis); (2) by-pass-valve obstruction in which the air passes in and out but in diminished amount. Here the asthmatoid wheeze can be heard near the patient's open mouth; (3) check-valve obstruction in which the air flows in one direction only and may cause either atelectasis or emphysema. The respiratory cycle is likened to a reciprocating pump which may fill or empty a given area in the lung. Resetting of the check-valve action may be caused by: $(a)$ shifting of a foreign body; (b) outgrowth of inflammatory or neoplastic tissue; (c) changes in the tissues that form the valve. Distant or absent breath sounds with an unimpaired or hyper-resonant percussion note justify a tentative diagnosis of check-valve obstruction. In children this is usually a foreign body; in adults it is more often due to abnormal secretions, inflammation, or new growth. The 


\section{Miscellaneous}

concurrence of distant or absent breath-sounds with an impaired percussion note often suggests check-valve or reverse check-valve obstruction, producing atelectasis. In cases of atelectasis the first thing to be thought of in children is a foreign body, and in adults a new growth. Removal of the obstruction, no matter how complete it may be, does not immediately restore function to the atelectatic area. Check-valve obstruction may be produced by various mechanisms, chief of which are: (I) foreign bodies; (2) benign growths; (3) malignant growths; (4) adenopathy; (5) anomaly; (6) inflammatory mucosal swelling; (7) granulations and granulomas; (8) secretions; (9) blood clots. The bronchoscope often reveals considerable quantities of secretions in the bronchi when there is a complete absence of dry or moist râles. Check-valve obstruction is commonly associated with diphtheria and most deaths are due to unrecognised respiratory obstruction. When atelectasis is bilateral, death is certain unless the bronchoscope is used. The author thinks the so-called cases of "black diphtheria" were of this type.

The article occupies eleven columns, is illustrated and has a bibliography.

Angus A. Campbell.

\section{MISCELLANEOUS.}

Diathermy Morcellement. Neze Technique and Apparatus. LuIS Samengo, Buenos Aires. (La Semana Medica, No. 28, r930.)

Morcellement is a dangerous procedure, which causes free bleeding and is rarely an operation of choice. It is to be condemned in the treatment of nasopharyngeal fibroma. This view of morcellement is quite altered by combining with it diathermy. It then becomes the method of choice, easy to carry out, safe and effective, because the diathermy forceps coagulate the tissues while they cut and the bleeding is trifling. It is not even necessary to use chloroform with the patient in the position of Rose. It can be done with local anæsthesia. It is particularly useful for removing tumours in awkward anatomical situations or in cavities where manipulation would be difficult. It is rapid and shock is much diminished; the tissues are sterilised, the lymphatic and blood vessels are shut off, and the bloodless field gives a better view and control. The paper contains numerous illustrations of forceps designed by Dr. Samengo for operating on the nasopharynx and the epiglottis. They are made of tungsten-steel, which is very resistant to the effects of sparking, are perfectly insulated, and can be sterilised dry.

L. Colledge. 


\section{Abstracts}

Dyscesthesia, Neuritis of the Pharyngeal Branches of the Vagus. Dr. Maurice Vernet, Paris, (Acta Oto-Laryngologica, Vol. xiv., Fasc. I-2.)

The time of paræsthesia-neuroses is past. Every organic sensation reveals an anatomical change in a definite limited nervous region, a functional disturbance, a more or less profound change which can be exactly determined. This is the case in disturbed sensibility of the pharynx which constitutes a dysæsthesia of the vagus in one of its most important branches.

Dysæsthesia, pain and palsy are the three successive symptoms of a more or less lasting neuritis of this nerve. The author describes exactly the sensitive innervation of the pharynx, the analysis of the experimental or accidental intersection of the last cranial nerves, and the systematic clinical observation of the different kinds of dysæsthesia of the vagus on which is based the description of this syndrome.

Furthermore, the author makes a study of the whole gradual ascent of the observed sensitive disturbances, from dysæsthesia up to pain. The fundamental character of these disturbances is that, contrary to the manifestation of pain in mucous inflammations, where the pain is increased through swallowing solid food, they are diminished by it. The pain which also appears in ordinary swallowing disappears in taking food and hot drinks.

Reflex secretory disturbances accompany the sense disturbance, i.e. dryness in the throat in prolonged dysæsthesia and excessive salivation in acute dysæsthesia.

Reflex congestive or ischæmic vasomotor disturbances without inflammatory character, whose temporary periodicity is parallel to that of the corresponding sense disturbance, also belong to the symptom-complex. This is also the case with the spasmodic or reflected atonic element which depends on sensibility disturbance. Local or general causes can give rise to dysæsthesia: tonsillolith or inflammation of the crypts, e.g. in the slight and unilateral cases, especially influenzal; herpetic diseases of the pharynx, disturbances in the ovarian function, etc., in cases of bilateral dysæsthesia. Patients suffering from these disturbances are only secondarily nervous patients because the etiquette of psychosis has too often hidden the real neuritis which is perfectly curable and a cause of the observed sensitive disturbances.

AUTHOR's ABSTRACT.

Incidence of Ragweed Pollen in United States during 1929. O. C. Durham, Indianapolis. (Journ. Amer. Med. Assoc., 14th June I 930, Vol. xciv., No. 24.)

In co-operation with the United States Weather Bureau the author attempted to make a national atmospheric pollen survey in 1929. The work was started loth August, continued in all stations until 218 


\section{Miscellaneous}

3 oth September, and in the southern stations until 3 Ist October. Petrolatum-coated slides were exposed, oiled side up, for twenty-four hours and changed daily. At weekly intervals the slides were counted. Graphs for each active station combined in geographic groups showed daily fluctuations from normal of wind, temperature, and sunshine. The more evident influences were latitude, soil, rainfall and local agricultural conditions. The potential ragweed district is the territory east of the Rocky Mountains except the south end of Florida, the worst district being the Mississippi valley. Seven species of ragweed were studied. Almost rigid dates of onset, climate, and termination of the season are rapidly being established and daily fluctuations of the pollen curve can be satisfactorily predicted on much the same basis as weather. Temperature ranked next to wind as the immediate determiner of the incidence of pollen.

The article occupies ten columns, has seven figures and three tables.

Angus A. Campbell.

Staphylococcus Toxin in the Treatment of Furunculosis : Preliminary Report. Ellwood C. Weise, Bridgeport, Conn. (Journ. Amer. Med. Assoc., and August r 930, Vol. cxv., No. 5.)

Twenty-four unselected patients of various types were treated. All had had recurrent furuncles from three weeks to eight years. All had active lesions at the time of treatment except two.

The toxin preparations for the treatment were prepared by Parker. They were diluted with physiological solution of sodium chloride in proportions of $I: 2, I: 5,1: 10$, and $1: 20$, and 0.5 per cent. phenol was added to the diluted toxin.

Hypodermic injections of diluted toxins were given at weekly intervals for ten doses. The initial dose was 0.5 c.c. of the $\mathbf{1}: 20$ dilution (about $2 \frac{1}{2}$ units). The amount was gradually increased at each visit provided that no marked local reaction was noted. When well borne the dose was worked up to I c.c. of a $I: 2$ dilution. Little or no reaction was noted at the first injection. Later ones were followed in from six to twelve hours by local redness, tenderness, and occasionally swelling. Favourable response to treatment was usually evident after four to six injections. Improvement manifested itself by rapid decrease in the size of the furuncles. If new furuncles appeared they were smaller than the previous ones and resolved more rapidly. Of the twenty-four patients treated nineteen ceased to have furuncles, and several of these who could be followed from three months to two years remained free. Diabetes was present in two cases which were uninfluenced. The remaining cases showed a decrease in the severity of the boils and a greater lengthening of the intervals between their occurrence.

The article occupies nearly five columns, has a bibliography and a table showing results of treatment. Angus A. Campeell. 